\title{
Fusing Community-Engaged Learning \& Transdisciplinary Curriculum for Undergraduate Community Development Education
}

\author{
Steven Kostell ${ }^{1}$ D $\cdot$ Kelly Hamshaw ${ }^{1} \cdot$ Thomas DeSisto $^{1} \cdot$ Jane Kolodinsky $^{1}$
}

Received: 9 November 2020 / Accepted: 28 June 2021 / Published online: 9 July 2021

(c) The Author(s), under exclusive licence to Springer Nature Switzerland AG 2021

\begin{abstract}
The Department of Community Development and Applied Economics at the University of Vermont embraces a transdisciplinary approach to community development education that provides students with real world experiences through community-engaged learning opportunities. The department was originally formed by an administrative decision that merged three departments in the College of Agriculture and Life Sciences intending to save financial resources. Over 25 years, we have developed a transdisciplinary approach that fills gaps that exist between disciplines that have yet to be closed while engaging with a variety of community partners to co-produce solutions to promote positive change. This article describes the evolution of our transdisciplinary curriculum that integrates a three-phased approach to service-learning. This framework enables faculty to offer appropriate service-learning experiences that provide meaningful interactions between students and community partners. CDAE has both honed and expanded curricular offerings to meet student interest and to better address community-based issues at the local, national, and global level.
\end{abstract}

Keywords Community Development · Wellbeing · Service Learning · Transdisciplinary Studies $\cdot$ Design $\cdot$ Curriculum

\section{Introduction}

Humanity faces a plethora of complex, vicious, and aggressive psychological, social, political, economic, and environmental "wicked problems": climate change, health pandemics, poverty, inequitable income and wealth distribution - among many others. Addressing these complex problems requires a synthesis of knowledge.

Steven Kostell

steven.kostell@uvm.edu

1 Department of Community Development and Applied Economics, The University of Vermont, Burlington, VT, USA 
The challenges affecting our communities and world are complex, interconnected, and ever-changing (Nicolescu, 2002, 2014), fueling the demand for professionals with a unique set of knowledge and real-world problem-solving skills (Klein, 2014). Transdisciplinary scholars go beyond a linear application of a static methodology and aim for an evolving, dynamic, or responsive methodology that is iterative and an ongoing part of the research process" (Wickson et al., 2006, p. 1,051). By loosening the reins on disciplinary thinking, transdisciplinary approaches may be viewed, in Nicolescu's words, as “...the science and art of discovering bridges between different areas of knowledge and different beings" (Klein, 2004; qtd. in Wickson et al., 2006, p. 1053).

Community development requires individuals who can think and act across disciplinary boundaries (Baker et al., 2009). Higher education institutions can contribute to the synthesis of knowledge and experience by offering transdisciplinary curricula coupled with applied experiences in the context of improving and supporting community wellbeing. This case study shares one department's evolutionary approach to equipping the next generation of community development professionals through a phased approach to community-engaged learning integrated within a transdisciplinary curriculum.

\section{Department Background}

Driven by the land grant mission, the College of Agriculture and Life Sciences (CALS) is home to the Department of Community Development and Applied Economics at the University of Vermont. CDAE faculty engage with each other, with faculty across the college, Extension professionals, educators, and researchers throughout the university. These practices cross diverse perspectives ranging from plant and soil science to food systems and social-ecological resilience to communication. We work collaboratively to engage local and global communities, government agencies, and researchers to co-produce and apply knowledge in a way that sustains communities, economies, and ecological well-being. Faculty draw on these transdisciplinary areas of expertise and breadth of experiences to teach and mentor students. From how to develop trust and cultivate a shared vision to collaboration within communities, organizations, and teams, CDAE contributes to the greater CALS' mission of supporting vibrant Vermont communities and strengthen the relationships between CALS faculty and extension, Vermont communities, and government agencies.

As a leader in innovative research with a solid foundation of community engagement and transdisciplinary practice, the department of CDAE has positioned itself to offer students an immersive educational experience, research, and community engagement opportunities for close to twenty-five years. CDAE provides a comprehensive curriculum to encourage the synthesis of concepts across curricular subject matter that include economic, social, and environmental principles to identify community needs, analyze problems, and advance sustainable solutions in partnership with for-profit, nonprofit, and governmental organizations and communities (Fig. 1). 
Fig. 1 The foundational principles of sustainable community development contributing toward community wellbeing

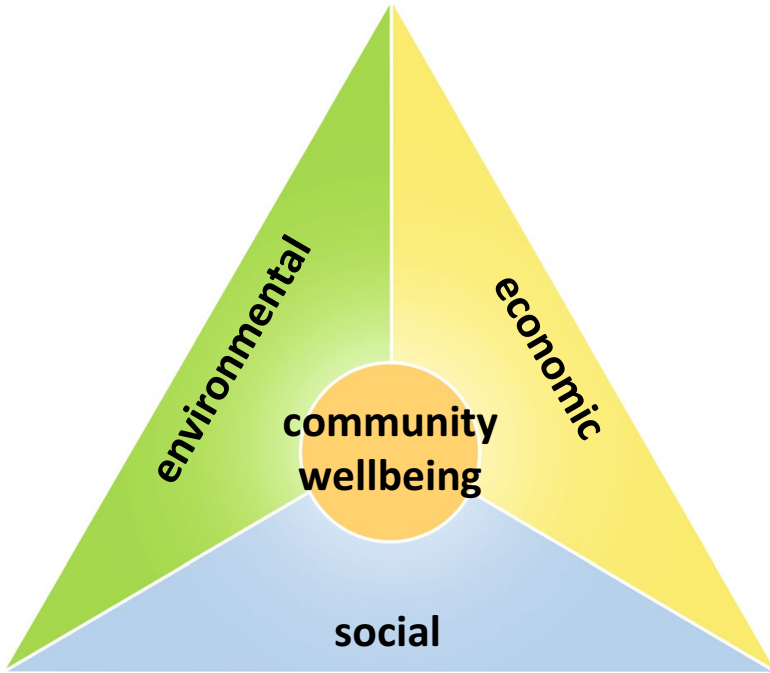

Classroom engagement remains a vital component of the land grant mission of teaching, research, and outreach. As local and global issues become increasingly complex, we have found ourselves ahead of the curve concerning teaching our students to become "doers" who possess skills in collaborative problem solving and systems thinking. CDAE students graduate as experts on the process of organizing teams, listening to stakeholders, contextualizing problems, and working together to conceptualize and implement new sustainable and responsible solutions using systems thinking approach. Process experts can connect people, ideas, and actions across traditional disciplinary boundaries to promote the wellbeing of their communities.

Since 2002, the number of undergraduate majors in CDAE has grown by more than 600 percent, while the number of minors grew by 400 percent. With typically no more than 30 entering first-time, first-year students, our department houses "discovery majors," found by students taking a course or hearing about our offerings from a peer. Today the department enrolls 450 undergraduate students in four majors; community and international development, community entrepreneurship, and public communication (Table 1), almost 200 minors in five areas, over 50 graduate students, 17 full-time faculty members, and a dedicated group of part-time faculty members, we have grown from a disparate group of faculty and majors to a unit focused on supporting sustainable local and international community development through interdisciplinary research, education, and outreach that serves the public interest." We believe that the public interest is best served by working across cultures and by defining sustainable development as ecologically based, economically sound, socially just, and ethically communicated.

Expertise among the CDAE faculty cuts across traditional disciplinary boundaries. Faculty members hold advanced degrees in agricultural, applied, behavioral and ecological economics, community development, communication, business administration, design, public administration, rural sociology. Many have professional and 
Table 1 Descriptions of the undergraduate majors in CDAE

\begin{tabular}{|c|c|}
\hline CDAE Majors & Brief Description \\
\hline Community \& International Development & $\begin{array}{l}\text { offers students a structured opportunity to jump into } \\
\text { the world and make a difference. Backed by rigorous } \\
\text { coursework and experienced faculty oversight, students } \\
\text { put ideas into action on the ground... here in Vermont } \\
\text { or all over the world. What they find is that real world } \\
\text { issues are more complex than they usually seem. There } \\
\text { are underlying social, economic, and cultural factors that } \\
\text { can hinder development or be an asset to it }\end{array}$ \\
\hline Community Entrepreneurship & $\begin{array}{l}\text { instills the foundations of successful micro and small } \\
\text { enterprise development including strategic business } \\
\text { planning, marketing techniques, and market analyses and } \\
\text { projections. As entrepreneurship is a vital thread in the } \\
\text { fabric of a community, students acquire entrepreneurial } \\
\text { skills in the context of social responsibility and healthy } \\
\text { community development }\end{array}$ \\
\hline Public Communication & $\begin{array}{l}\text { uses communication to inform and persuade, to build } \\
\text { relationships, and to encourage open dialog in organiza- } \\
\text { tions and communities toward resilient solutions. This is } \\
\text { accomplished by crafting successful messages through } \\
\text { the application of research, theory, technical knowledge, } \\
\text { and sound design principles. Students majoring in Public } \\
\text { Communication use an integrated, hands-on approach to } \\
\text { communication in the public interest to critically analyze } \\
\text { situations, manage information, and craft messages that } \\
\text { work in an increasingly global society }\end{array}$ \\
\hline
\end{tabular}

community experiences that align with their academic careers. Faculty bring valuable applied experiences from the fields of regional planning, non-profit organizational development, and public health communication and from volunteer service in the U.S. Peace Corps and AmeriCorps. As a transdisciplinary department, CDAE offers a wide variety of courses ranging from entrepreneurship and consumption economics to community planning and strategic writing for public communication. The eclectic yet synergist nature of our faculty is essential to offering our students a cohesive and relevant curriculum that prepares our students to become effective agents of change in their lives outside the University.

\section{Integrating Community-Based Service Learning into the Undergraduate Experience}

The CDAE undergraduate curriculum is designed to expose students to a transdisciplinary core as the foundation of each of the four majors. All students must complete the CALS distribution requirements, as well as the current CDAE core courses (required for all CDAE majors), which introduces students to local and global community issues, provides a foundational knowledge of the consumption, production, and regulatory issues of human behavior uses research methods to explore social dynamics, and provides opportunities for service learning and communication. 
The 19-credit core curriculum (Table 2) provides an interdisciplinary foundation, building toward specialization as students advance through their majors. Six courses within the core curriculum provide students with an understanding of issues affecting the health, well-being, and sustainability of communities-from local to international contexts. Courses also include fundamentals of communication, design, economics, public policy, and research methods. This content teaches students about theories, skills, and contexts for complex issues facing local and global communities, (including climate change, social inequity, organizing, and sustainable community development). The CDAE core curriculum also introduces students to CDAE's central theories, values, and practices, including community engagement, effective communication, transdisciplinary research, and applied economics. These perspectives will be explored in-depth and reinforced as the student advances through the coursework within their chosen major.

The major area of study curriculum teaches students about the theories, mindsets, and practices associated with creative problem solving, as well as contemporary approaches to social innovation. Students learn innovation skills that are widely applicable to different domains and content areas. These skills include conducting primary research, critical thinking and data analysis, idea generation, prototyping with physical and digital materials, managing team dynamics, and presentation/communication skills. The human-centered design approach offers students the opportunity to increase idea generation, co-creation, and multidisciplinary exchange and convey more flexible and open to new process approaches (Minder \& Heidemann Lassen, 2018). Drawing on theory, case studies, and applied practices, students engage in service-learning experiences, which are action-oriented and encourage an experimental and iterative approach to solving open-ended problems with community stakeholders. Frameworks for innovation and creative problem-solving methodologies enable interdisciplinary teams to tackle complex, open-ended challenges (Barry \& Beckman, 2007) across many different domains (Kolko, 2015). As such, it helps students develop resilience, and strengthen their ability to give and receive constructive feedback in realworld situations. This practice engages students to adopt crucial $21^{\text {st }}$-century skills such as creative idea-generation; effective collaboration and teamwork; and communication and presentation skills.

Table 2 CDAE required core curriculum

\begin{tabular}{ll}
\hline $\begin{array}{l}\text { Suggested } \\
\text { year of study }\end{array}$ & Required course \\
\hline 1 & CDAE 002-World Food, Population \& Development \\
1 & CDAE 024-Fundamentals of Public Communication \\
1 or 2 & CDAE 061-Principles of Community Development \\
2 & CDAE 102-Sustainable Community Development \\
2 or 3 & CDAE 127-Consumer, Markets \& Public Policy \\
3 or 4 & CDAE 250-Research Methods (4 credits) \\
4 & CDAE 2XX-Capstone (3 credits-major specific) \\
\hline
\end{tabular}




\section{Adopting a Phased Approach to Service-Learning}

Every undergraduate student in CDAE is required to engage in service-learning/ field experience, embedded in capstone courses, international travel courses, and complimented through internship opportunities. It is important to recognize that service-learning courses require faculty members to develop community partnerships, invest in communication, and provide mentoring to their students. In the department's early years, when enrollments were relatively smaller, providing these intensive learning experiences was feasible. However, as enrollments grew and more faculty sought to offer service-learning experiences, it became necessary to examine how and where service-learning was occurring within the curriculum.

In collaboration with the Office of Community-University Partnerships, CDAE embarked on a reflective curriculum mapping exercise where service-learning occurred within the curriculum and found that it was not equally integrated across the three majors. A survey of faculty members found that nearly all had taught a service-learning course yet were encountering capacity challenges, such as lack of planning time, communication issues, and conflicts arising within student groups (Westdijk et al., 2010). These findings led to the department assessing the types of service-learning experiences within the department's offerings and a strategic conversation about adopting a phased approach to service-learning (Williams Howe et al., 2014) based on student development theory. This approach features the integration of different phases of experiences where students can make a graduated progression from very structured service-learning courses during their first or second years while gaining important knowledge and skills that would then be applied in more advanced service-learning classes later in their curriculum where they may work more independently with their community partner. Service-learning requires significant investments from students, faculty members, and community partners alike. CDAE faculty have adopted the three-phased approach to engaging students in service-learning projects related to community wellbeing (Williams Howe et al., 2014). This approach is grounded in student development theory to ensure that faculty members are designing course experiences that are appropriate for the students' levels of knowledge and skill while ensuring that community partners benefit from this reciprocal endeavor. The Department has embedded courses for each of the three phases across the curriculum so students can have meaningful community engagement experiences throughout the arc of their CDAE academic career (Fig. 2).

Today in CDAE, students are engaged in service-learning concepts from foundational courses through the capstone experience. Pedagogical goals share a consistent framework while allowing for flexibility in engagement models. Additionally, CDAE faculty cultivate and sustain valuable relationships with community partners from local communities in Vermont to non-governmental organizations abroad. Partnership development is based on reciprocity, meeting community partner interests/needs while providing students an opportunity to gain new knowledge and experiences. Exposure is reciprocal, between our students and 

Phase 1
Phase 2
Phase 3
Exposure
Capacity Building
Responsibility

\section{CDAE Core Curriculum}

\section{Major area of study courses}

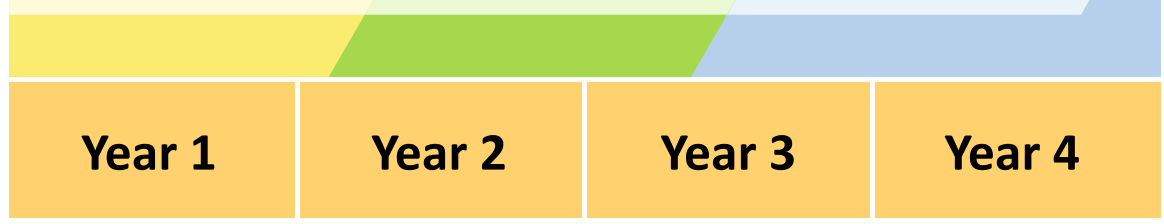

Fig. 2 The CDAE Curricular Framework: Integrating the phases of service learning across the undergraduate curriculum

the communities we serve. Capacity building among partners seeks to align our expertise to match community needs. Responsibility is modeled early in the curriculum and increases in advanced service-learning courses as students take on project leadership roles.

\section{Curriculum Highlights: Engaging Students Through the Lens of Community Wellbeing}

Communities-rural and urban, local, and global-are the laboratories for CDAE's research. The three majors available to students give them a solid foundation in applied economic principles, communication, community development and policy analysis. Students discover what it means to be entrepreneurial, regardless of their major and are introduced to methods used to develop communities that are economically, socially, and environmentally sustainable. They engage with policymakers and community leaders to gain insight into governance and policymaking processes. Students form connections with local, regional, and international mission-driven organizations that seek to improve quality of life.

The following projects exemplify the department's adoption of the ThreePhased Model for Course Design approach that guides its service-learning offerings embedded throughout the undergraduate curriculum (Williams Howe et al., 2014). The approach considers how goals, the instructor's role, project scope, and connection to academic content evolve as students' progress through 
the curriculum. Williams et al. Provide guidance for designing service-learning experiences that are developmentally appropriate for students at each phase. This section presents examples of course experiences that illustrate each of the three phases: 1) Exposure, 2) Capacity Building, and 3) Responsibility (Table 3).

Table 3 Adapted from Three-Phased for Course Design, Williams Howe et al., 2014

Phase 1:

Exposure

Phase 2:

Capacity Building

Phase 3: Responsibility
Goals: introduction/exposure to service-learning and course content; initial skill development (teamwork, project management, interacting with community); introduction to reflection as academic practice; building cultural and interpersonal competencies

Instructor Role: Primary Manager-defines project (in collaboration with community partner), carefully controls student interaction with partner, provides close guidance throughout the process, outlines clear processes and expectations

Project Description: clearly defined, concrete, small in scale, time limited, often happen within the classroom, rather than in the field. Can also be "hypothetical" (not considered service-learning, but preparation for service learning)

Connection to Academic Content: content is primary focus, project explicitly connected

Goals: building student capacity, raising expectations, increasing student responsibility for outcomes; practicing personal/professional skills introduced in earlier courses; progressing to higher levels of critical thinking through reflection

Instructor Role: Facilitator-continue to provide structure (tools, timelines, and reporting) but raise expectations for students to self-manage within this structure; select partners and establish agreed-upon outcomes, but welcome student participation and input in the process

Project Description: major component of the course (a unit or major project); may focus on an extended relationship with an organization (an enhanced internship or field-based experience); expectations are defined, but students take leadership in deciding how to meet them

Connection to Academic Content: explicit, but challenges students to find additional connections, synergies, and critiques. Balance between focus on content and application

Goals: skill mastery, professional development, student accountability/ responsibility for outcomes, independent decision-making, effective group work, problem-solving; mastering higher levels of critical thinking through reflection

Instructor Role: "Coach"-empowerment with support; provide suggestions/ tools for structure, ongoing consultation, but raise expectations for students to follow-through and seek resources on their own. Keep "in touch" with projects and partners to monitor progress

Project Description: developed collaboratively between partners and students, with faculty input; require students to take high-level responsibility for defining, understanding, and working to address an issue; often span an entire semester or year; could focus on "deliverables," programs, initiatives, or ongoing professional roles within an organization

Connection to Academic Content: students are demonstrating knowledge of content through projects. While content is still delivered, it may be driven by topics that support projects and related to transitions to professional roles 


\section{Phase 1: Exposure}

Introducing students to service-learning principles and projects in the classroom establishes the foundation for understanding systems interactions by identifying stakeholders and understanding stakeholder needs. Students engage with community members to learn about and understand community issues, and the economic, social, environmental, political, psychological, and other impacts associated with alternative courses of action (Kuh, 2008).

The foundation of service learning is established in the classroom. Embedding human-centered design principles into Phase 1 courses introduces group creative problem solving with a focus on community-based systems. Contextualizing undergraduate projects within the framework of a multi-stakeholder perspective allows students to strategically identify individuals and elements that contribute to the complexity of a system or process. Students receive a design brief, are introduced to strategies for interviewing stakeholders, and then go out of the classroom to observe and record interactions to gain an understanding of behavioral patterns, social norms, and community-system interactions.

Developing and sustaining partnerships with stakeholders across campus serves as an entry point for students' understanding of complex organizations, of which they are themselves, participants. Through on-campus partnerships with non-academic units, students begin to understand an organizational structure, experiencing the functions of a university services unit that may otherwise remain invisible or in the background of their everyday campus experience. This provides a new view into a system, of which they are already familiar as a participant. Containing the project on campus expands the boundary of the classroom, creating a convenience of proximity, enabling students to readily engage in preliminary surveys, record observations, and seek stakeholder feedback.

This first example demonstrates the introduction of service-learning concepts into the classroom, by presenting a low-stake community-centered design challenge with a potential measurable impact. The intent is to encourage rapid ideation, experimentation, iteration, and prototype generation toward potential solutions to a predefined community-based issue. For the past two years, in CDAE 018: Communication Design I, students are introduced to campus facilities Manager of Recycling and Zero Waste. A formal presentation of recycling processes and policies impacting on-campus waste stream mitigation identifies necessary steps toward a zero-waste campus environment. Students are introduced to the concept of stakeholder needs by being asked to explore the design question of "how to affect change in student behavior to reduce waste?" This challenge provides a scaled approach to tackling problems within a defined context, to address community needs from both service providers and systems participants. While students were presented with the challenge through the lens of waste stream mitigation, they were charged with developing creative communication strategies to encourage proper recycling, composting, and landfill waste separation, to mitigate cross-stream contamination at refuse collection points in the student union food court, residence hall dining facilities, and other on-campus food access points. 
Students surveyed the physical site, interviewed stakeholders, documented behavior, and began the brainstorming process. Project proposals ranged from printed infographics to multimedia displays, and gamification through simulated mobile apps. Student groups were tasked with implementing ideas into the environment, enact community initiatives and determine efficacy through direct observation. Campus facilities collects periodic data through waste audits and presents that data to the students at the onset of the project each year. Given the immediate proximity of the classroom to the campus community, stakeholder feedback is readily accessible, processes are easily observable, and soliciting stakeholder feedback through an iterative design process begins to draw evidence of the relationship between messaging and waste separation behaviors at the local community level.

Another method of introducing service-learning concepts in the classroom is to engage other faculty researchers as process experts. This allows faculty to present specific on-going research projects, often within the context of international community development. For this project-based learning in CDAE 116: Communication Design II, a research faculty is invited to partner with the class, introducing a framework to address a complex set of variables that reveal the emerging needs of separate, yet inter-dependent communities. Information is presented from a multi-level perspective, identifying stakeholder groups, cultural complexities, policy perspectives, socio-technical relationships, and specific identified community needs that resulted from the research work.

The case is introduced as an active multi-disciplinary collaboration between agricultural producers, agricultural workforce, government, and non-government agencies. Focusing on the tea industry in Sri Lanka, the faculty researcher, provides an overview of, and detailed insights into the agronomic systems of production, processing, environmental impact, labor needs, available workforce, workforce training, governmental policies, and socio-cultural relationships. Students are presented demographic data, data on technology adoption, description of the training programs, and expressed community needs from a multi-stakeholder perspective. Students are tasked with designing an app that will allow stakeholders to communicate across stakeholder groups to coordinate agricultural production, linking the stages between farm-gate to markets, as well as inclusion of access to and tracking of training/certification for both producers and workforce.

Students begin by mapping the system, identifying necessary functionality toward a solution that meets the needs of multiple stakeholders, linking communities, addresses sustainable farming practices and market influences. Students quickly generate a wireframe flow diagram to navigate relationships and simulate interactions, working through iterative stages of visioning and prototyping new interfaces for communication interactions between workforce, producers, and markets across the industry, bridging geographic regions and developing modes for various technical certification programs - translating concepts into a final design for a simulated user interface/user experience (UI/UX) proposal. Final design solutions are presented to the faculty member, who in turn shares with selected projects to community partners, to further dialog between stakeholders and ultimately toward an implementable solution. 


\section{Phase 2: Capacity Building}

The curricular and co-curricular activities developed in CDAE employ high-impact practices of project-based learning, service-learning, and collaborative research. CDAE is a pioneer of UVM internship experiences, and our community connections run deep. The CDAE Internship Program supports students to find internship experiences locally, nationally, and internationally. Internships allow students to gain relevant experience that they can apply to a future career and inform a critical perspective in the students' undergraduate experience.

Students in the Community Development and Applied Economics department actively seek out experiential learning opportunities such as internships to apply what they are learning in the classroom to a real-world setting, develop transferable skills, and explore potential careers. CDAE students intern with businesses, government agencies, and non-profit organizations both locally and nationally.

Since the fall of 2018, CDAE 296 (the department's internship course) had 348 students register their internships for academic credit: 135 of those students interned with businesses, 28 with government agencies, 107 with non-profit organizations, and 76 with the University of Vermont and University of Vermont Extension (Fig. 3).

\section{Building Capacity Through International Service Learning in Kenya}

Since our inception, CDAE has been involved in international service-learning. The approach is a hybrid. Our approach is not a semester abroad in which students disengage from their current University to enroll elsewhere for a semester or academic year. Neither are they "travel trips" that occur over a Spring Break, although the

\section{CDAE Internship Placement Types}

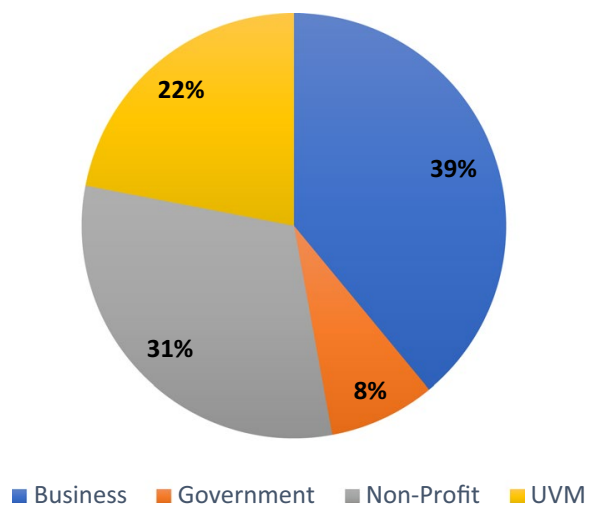

Fig. 3 Internship placements for CDAE students (2018) 
actual travel portion of the class may occur over the winter break, spring break of immediately after the spring semester. What sets the CDAE international servicelearning courses apart? These are semester-long courses, with partner continuity over time, where community development projects are co-created and implemented. The point of entry depends on the level of the relationship. With new partners, reconnaissance and trust building are typical in the first year. Projects sometimes emerge based on the need of the community in consort with the course and sometimes are suggested by the community. Regardless, fit, ability, and availability of resources are key components of decisions surrounding project choices-for both the students and the community. This is a type of "matchmaking" That requires faculty/partner leader cooperation. Relationships and projects are built to continue over time. The semester approach for a given class allows the development of a project and team building. Built into these relationships with partners are project building, implementation, and debriefing. Because all courses have a community development lens, the process of community development is important. We have yet to experience a partnership where a community need is not matchable to student/faculty expertise.

One course that was developed and implemented over four years, with student travel in years two through four, is our Sustainable Development and Education course in both a remote rural community and urban city in Kenya. This class enrolls 12-15 students, and the teaching is shared by a CDAE faculty member and a faculty member in the Department of Nutrition and Food Sciences. UVM student groups were paired with students from a high school in Nairobi, Kenya and a rural community in western Kenya. While it took three years of development, the fourth year is when all pieces fell into place and final project implementation occurred. In the first year, faculty members built trust with a new partner and travelled to identify whether student travel was possible in terms of safety, logistics, and probability of success. In year two, students participated, not in the completion of a project from inception to completion, but in the process of community development. For example, in the second year, introductions were made, and cultural competency built. Student projects focused on international understanding and cultural competence. Both Kenyan and UVM students realized the importance of reciprocity-learning took place on both continents. The final projects included documentation of the process of community development and the landscape Future students would encounter. These projects were passed on to the next student cohort. In the third year, both the UVM faculty and Kenyan leaders agreed on public health, women's empowerment, and food systems as project components. Together, the UVM and Kenyan students met via the internet during the semester and worked together to build skill and deliver demonstrations in the chosen areas. In the final year before COVID-19 caused the cancellation of all travel, Kenyan and UVM student partners worked on building a cold storage unit that did not require electricity, on a grain mill and break-even analysis for the community, and passing cultural foods knowledge across generations, and on documenting the process. These final projects grew out of community need, the expertise of the students/faculty, and available resources. Students with majors in engineering, public communication, nutrition and food science, and community and international development were registered in the final cohort. There is no magic formula to the success of these experiences. Flexibility, knowledge of the community, 
and building on assets are required. That said, knowledge is built across cohorts, paving the way for the next class, trust is built with partners, and projects emerge that meet the needs of BOTH the community partner and the university course.

What are the components of the course regardless of where we are in the process of building continuity with a partner? One of the first readings is Green and Anna Haines (2016), chapter 4 in Asset Building and Community Development. Based on this, reading, a first student assignment is to build a logic model and discuss what they believe is the first and most important step in building assets. The logic model serves as a road map to fill in as the course develops. Typically, students can easily identify inputs and outputs. As the semester progresses, they fill in actions and outcomes. The ideal scenario is that students "meet" with their international student partners several times during the semester. This is often difficult due to time differentials, technology glitches, and unexpected issues. For our students, this third year in the field had more pre-departure communication with our partners, a better understanding of projects, and overall students felt more prepared.

Where do resources for such experiences come from? Our students also learn about the seven community capitals: social, human, environmental, political, cultural, natural, and financial. Our students struggle each year with the idea of raising financial capital for projects and the idea of charity versus community development. In 2019, A community fundraising initiative by a non-profit raised funds for a grain mill for the community and materials for the evaporative cooler. The student project was to calculate breakeven points for the use of the grain mill, work with the community to build the cooler, thus aiding with technical skills transfer and not charity. A foundation of all of our international community development courses is that we do not "save" a community, as much charity work does. Our goal is to work closely with communities to help them develop sustainable solutions based on their needs and available resources.

\section{Phase 3: Responsibility}

In Phase 3 courses, students have a greater level of responsibility throughout the arc of the service-learning project. Faculty members and community partners have greater expectations for students to be able to work more independently, applying their content knowledge and skills to real-world projects, with support as needed. These intentionally designed experiences provide mark an important transition point as they prepare for graduation and launching their careers.

\section{Local Community Initiatives: A Capstone Service-Learning Experience}

Capstone courses within each major aim to provide students with a summative experience that provides a bridge from classrooms to communities. The State of Vermont provides ample opportunity to engage CDAE students in real-world, on the ground community development efforts. The small scale of Vermont offers 
the ability to network with stakeholders and decisionmakers with relative ease. CDAE faculty have developed longstanding partnerships with local government officials, state government agencies, community planners, locally owned businesses, non-profit organizations, and grassroots community groups. These partnerships enable CDAE to have a broader geographic reach beyond the University and its immediate surroundings.

The capstone course for the Community \& International Development major, CDAE 271: Local Community Initiatives, has partnered with several organizations within a rural community nearly an hour from campus over five years. The organizations include a community-based organization that is dedicated to promoting a vibrant downtown district, a volunteer-led community land trust, the local teen center, a volunteer-run recreation club, and the town's Recreation Department. The faculty member initiates project planning with each of the partners to identify potential projects that meet their needs and priorities while also ensuring that project scopes are manageable within a semester's timeframe. Before arriving in the community, the student teams read the community's municipal plan and the class uses the "community capitals" framework to identify community assets and develop a list of key questions for their initial field visit to meet with their community partners. During the field visit, students meet their community partners while also gaining a sense of the greater community. The student teams, with support from the faculty member, then refine the scope of their project with their community partner, refine their expected deliverables, and develop a work plan. This transition is critical for students to step into more of a leadership role with greater project management and communication responsibilities as they prepare for their post-graduation professional careers.

Examples of past projects include gathering data and interviewing local businesses to update the designated downtown plan, conducting visitor intercept surveys for the land trust, engaging local youth as part of a strategic planning process for the local teen center, and mapping the development of a community trail system. Depending on the nature of their specific project, some teams will need to return to the community for additional independent fieldwork while others can complete their projects off-site. The students share weekly project updates within the class in a manner akin to a staff meeting while also providing regular updates with their community partners. At the end of the fieldwork, the students meet with their community partners to present their deliverables and critically reflect upon their experiences. For many students, this course experience may be their primary interaction with a rural community outside of Burlington. Student reflections at the end of the course highlight how their service-learning experiences in this community emphasize the importance of relationship-building to the practice of community development as well as being inspired by their community partners' passion for improving quality of life within their community. This approach requires significant investments of energy from all participantsfaculty members, community partners, and students. 


\section{Cultivating Responsibility Through International Service Learning in St. Lucia}

CDAE has engaged in a mutually beneficial partnership and collaboration with the government and people of a Caribbean nation, through a formal Memorandum of Understanding (MOU). This collaboration began in 2003 when a government representative met with a CDAE representative at a research conference and expressed interest in partnering for the mutual benefit of the citizens of the island nation and CDAE faculty, staff, and students.

During the first three years of the collaboration, CDAE faculty, and staff members and a small number of students traveled from the US to the island to (a) visit potential project sites, (b) develop social connections, (c) explore various topic areas of interest, and (d) built professional partnerships. Multiple groups of government representatives from St Lucia traveled to the University of Vermont. Typically, the group sizes were small, ranging from 4 to 12 people, and lasted approximately 14 days.

The focus of the work during this reconnaissance stage was on social networking, project exploration, and capacity building. CDAE representatives provided several multi-day trainings and workshops on several topics related to development and research. In turn, government representatives and community members presented their work and projects to the CDAE representatives. Formal and informal reflection and assessments were used to make sure that the process was understood and critically examined by those involved. The relationships that were formed, the capacity that was built, and areas-of-interest that were identified during this stage formed the foundation for all future collaboration.

In years 4 to 8 , the foundational work was built upon with more well-defined, multi-year projects at field-sites in multiple urban and rural areas in the host country. The visits to the island and the UVM campus remained at approximately 14 days. The number of government representatives remained the same, while the number of faculty and staff decreased from four to two, and the number of students increased from less than 12 to between 13 and 20. During the project work, student teams ranged in size from 2 to 6 people who were partnered with 2 to 6 government representatives and local partners. Workdays begin at 7:00 AM and end at 7:00 PM. The knowledge and skills that were shared and exchanged between partners were put into use during community development projects.

One major policy that was developed and set in place during this phase was that project supplies should be sourced in-country, and not imported from abroad. The reason for this was to make sure that local partners would be able to maintain and replicate any work that was done. An emphasis on the transferability of the projects from the community to the community within the island was emphasized and promoted.

The participant reflection process was formalized during this phase. Students engaged in nightly oral and written reflection, responding to prompts developed by the faculty, staff, and students based upon ideas, issues, and questions raised during the workday. These regular, responsive reflections were critically 
important to both the educational and project success during this stage. The reflections enabled students to connect concepts from their previous coursework to their current projects, but even more importantly, they were able to hear from other students about their own, unique experiences from the day. One major takeaway was that students would assume that everyone had a similar experience to theirs, and they were often surprised to hear about differing experiences or perspectives. Faculty and staff meet twice or more per day to reflect and assess the project work and partnership, while government and community representatives spoke with the CDAE faculty daily.

From Year 8 onwards, the collaboration and partnerships have moved into a stage of maturity. The faculty and government representatives have worked together for many years. Professional relationships have been solidified through countless projects.

The structure of the relationship and travel has also been standardized. Two faculty members work with 14-16 students over the length of a semester and then travel to the island for exactly 11 days. The project teams are made up of 3 or 4 students, and 3 to 4 government and community partners. The teams are smaller to maximize small group communication and task efficiency. The trip lengths were shortened from 14 to 11 days to concentrate the efforts of the intense 12-h workdays. CDAE and government representatives still engage in day-long training and workshops, but in the local community instead of in the USA at the UVM campus to reduce the time and administrative burden of travel. Reflection and assessment are still used as described during the Building Stage and have led to discussions about how to expand this partnership to neighboring islands.

\section{Outcomes and Impact}

The Department's commitment to the development of a transdisciplinary curriculum (Baker et al., 2009) and its adoption of the phased approach of integrating servicelearning throughout the undergraduate experience has led to longstanding partnerships with community organizations and a growing network of alumni engaged in community-based work. The intentionality of creating phased community engagement and service-learning experiences that align with student development milestones (Williams Howe et al., 2014) allow students to have meaningful educational experiences in ways that maximize our community partners' experiences and investments.

The department conducts an alumni survey as part of its regular assessment cycle. Regarding three of CDAE's core teaching and learning goals (learning transdisciplinary theories, methods, and tools, engaging in service learning, and integrating applied economic, ecological, and policy principles in advancing sustainable community development), a strong majority of students rate these as at least somewhat important to their professional success. Of CDAE's undergraduate majors, $73 \%$ rated learning transdisciplinary theories, methods, and tools that support sustainable and ethical community development as at least somewhat important, $87 \%$ rated engaging in service-learning opportunities supporting community development as at 
least somewhat important, and 77\% rated integrating applied economic, ecological, and policy principles in advancing sustainable community development as at least somewhat important to their professional success. Many undergraduate students are not experienced in the work force and yet these responses display the belief among students that what-and how-they are taught in CDAE will apply to their professional lives. As students enter the workforce-as indicated by the results of the alumni survey-these responses are consistent with a slight increase in overall importance once students enter the workforce: $77 \%$ find Learning transdisciplinary theories, methods, and tools that support sustainable and ethical community development at least somewhat important, 93\% find Engaging in service learning opportunities supporting community development at least somewhat important, and $82 \%$ find Integrating applied economic, ecological, and policy principles in advancing sustainable community development at least somewhat important to their professional success.

Most CDAE courses expose students to both problems and solutions facing many sectors of society. Students take these tools and hone them through their time at UVM and experiences after they graduate. An alumni survey conducted in 2016 found that $86 \%$ of alumni of the CDAE programs who are pursuing their careers are doing so in fields or sectors that align with their CDAE academic program. Of the same group, $87 \%$ said their career is advancing as expected, faster than expected, or much faster than expected. Our alumni are dedicated to their fields and that they are advancing as expected or faster certainly indicates a penchant for learning and excelling in fields far beyond their time in CDAE.

\section{Looking Toward the Future}

Since its creation 25 years ago the Department of CDAE has offered an undergraduate curriculum spanning multiple design areas. The CDAE faculty have committed to the continued development of design as a critical part of the CDAE curriculum. CDAE has been an innovative, transdisciplinary department. The department is in constant evolution. Faculty have noticed this trend within and across our diverse disciplines. Many faculty members have already engaged in systems analysis and invested in design processes and applications. Today the Department offers courses, minors, and concentrations related to, but limited to topics in applied design, green building, policy design, design research, organizational design, strategic campaign design, social innovation, transition design, and communication design.

The introduction of a new curricular offering in design brings with it a theoretical framework that includes processes needed to "[devise] courses of action aimed at changing existing situations into preferred ones" (Simon, 1982, p. 129). Traditionally, design processes have been used to create new products or material structures. In CDAE, design is being applied to abstract entities, such as systems and services, as well as to devise strategies, manage change, and solve complex issues. Contemporary applications include a variety of social contexts and applications ranging from community resilience and communication to leadership processes and entrepreneurial ventures (Kummitha, 2019). In CDAE, design focuses on human and community-centered processes that optimize one's mindset and the creative collaborative 
practices to identify and address complex local, national, and global issues (Brown \& Wyatt, 2010).

This new major in Community-Centered Design will offer students the ability to develop an advanced understanding of the theory and skills that support humancentered processes to identify opportunities for innovation, creative problem-solving, connecting with other expert and nonexpert groups, and sharing new ideas and ways of organizing for positive change. Furthermore, students learn the principles of applied design and relational design, which draw on the ethical aspects of the design process, social change, and the impact of innovations on communities and their built and natural environments. It is intended that this new focus will bridge departmental curriculum, to grow the field of designers as facilitators of reflective processes (Minder \& Heidemann Lassen, 2018) toward social innovation and resulting community wellbeing.

\section{Conclusion}

Service-learning is a dynamic process that requires faculty investment, community investment, and student investment. Intentional partnerships develop over time, presenting both opportunities and challenges. As reflective practitioners, we actively evaluate whether we are asking the right questions. We must be aware of leading students as partners, working with communities to identify needs, co-design viable actions and set a course toward feasible outcomes. We recognize that communities have agency to share their priorities, and that we have an obligation to those communities to work within our abilities. As projects evolve over time, sustaining local or international partnerships present many logistical challenges. Time demands and balancing priorities are often met with financial constraints and resource limitations.

Drawing on our current course offerings and faculty expertise, the Department of CDAE seeks to prepare the next generation of community development leaders. The department offers students the ability to develop an advanced understanding of the theory and skills that support community wellbeing in terms of identifying opportunities for innovation, creative problem solving, connecting other experts and stakeholder groups, sharing new ideas, products, services, and ways of organizing for positive change. Throughout the undergraduate experience, applied and relational design principles draw on the ethical aspects of the design process, social change, and the impact of innovations on communities and their built and natural environments.

Contributing to the transdisciplinary approach is the convergence of knowledge through the CDAE framework, founded on the principles of sustainability, integrating the phases of service learning across a transdisciplinary core curriculum, and a focused area of concentration through the selected major. In CDAE, students are often required to address projects in teams, where it is encouraged for each students' contribution to synthesize individual knowledge with those of others, to gain new insights and small-group experiences. Students are actively engaged in co-creating solutions with communities, both urban and rural, and at the local, regional, national, and international levels. 
The Department of Community Development and Applied Economics is a leader in the application of learning and teaching techniques associated with design methodologies, including service-learning courses, mixed discipline team projects, and project-based assignments. The department's phased approach to integrating service-learning experiences throughout the curriculum provides students, faculty members, and community partners with meaningful opportunities for collaboration.

Authors' Contributions Not applicable.

Data Availability Not applicable.

Code Availability Not applicable.

Declarations

Conflicts of Interests/Competing Interests The authors have no conflicts of interest to declare that are relevant to the content of this article.

\section{References}

Baker, D., Koliba, C., Kolodinsky, J., Liang, K., McMahon, E., Patterson, T., Wang, Q. (2009). Land grant system: A case study. North American Colleges and Teachers of Agriculture Journal, June 2009, 34-42.

Barry, M., \& Beckman, S. L. (2007). Innovation as a Learning Process: Embedding Design Thinking. California Management Review, 50(1), 25-56.

Brown, T., \& Wyatt, J. (2010). Design thinking for social innovation. Stanford Social Innovation Review. https://ssir.org/articles/entry/design_thinking_for_social_innovation. Accessed 19 Aug 2020.

Green, G., Anna Haines, A. (2016). Asset Building \& Community Development. Sage Publications.

Klein, J. T. (2004). Prospects for transdisciplinarity. Futures, 36(4), 515-526.

Klein, J. T. (2014). Discourses of transdisciplinarity: Looking back to the future. Futures, 63, 68-74.

Kolko, J. (2015, September). Design Thinking Comes of Age. Harvard Business Review, 66-71.

Kuh, G.D. (2008). High-impact educational practices: What they are, who has access to them, and why they matter, $A A C \& U$.

Kummitha, R. K. R. (2019). Design thinking in social organizations: Understanding the role of user engagement. Creative Innovative Management, 28(1), 101-112. https://doi.org/10.1111/caim.12300

Minder, B., \& Heidemann Lassen, A. (2018). The Designer as Facilitator of Multidisciplinary Innovation Projects. The Design Journal, 21(6), 789-811. https://doi.org/10.1080/14606925.2018.1527513

Nicolescu, B. (2002). Manifesto of Transdisciplinarity. State University of New York Press.

Nicolescu, B. (2014). Methodology of Transdisciplinarity. World Futures, 70(3-4), 186-199. https://doi. org/10.1080/02604027.2014.934631

Simon, H. (1982). The Sciences of the Artificial (2nd ed.). MIT Press.

Westdijk, K., Koliba, C., \& Hamshaw, K. (2010). Collecting data to inform decision making and action: The University of Vermont's faculty community engagement tool. Journal of Higher Education Outreach and Engagement, 14(2), 5.

Wickson, F., Carew, A. L., \& Russell, A. W. (2006). Transdisciplinary research: characteristics, quandaries and quality. Futures, 38(9), 1046-1059.

Williams Howe, C. W., Coleman, K., Hamshaw, K., \& Westdijk, K. (2014). Student development and service-learning: A three-phased model for course design. International Journal of Research on Service-Learning and Community Engagement, 2(1), 44-62.

Publisher's Note Springer Nature remains neutral with regard to jurisdictional claims in published maps and institutional affiliations. 